\title{
Stenotrophomonas maltophilia: a new potential biocontrol agent of Ralstonia solanacearum, causal agent of potato brown rot
}

\author{
N. A. S. Messiha $\cdot$ A. D. van Diepeningen • \\ N. S. Farag · S. A. Abdallah · J. D. Janse $\cdot$ \\ A. H. C. van Bruggen
}

Received: 20 September 2006/Accepted: 19 March 2007/Published online: 15 May 2007

(c) KNPV 2007

\begin{abstract}
Stenotrophomonas maltophilia was isolated from the rhizosphere of eggplant in the Nile Delta of Egypt, and its antagonistic potential against Ralstonia solanacearum race 3 biovar 2, the causal agent of potato brown rot, was in vitro evaluated on
\end{abstract}

N. A. S. Messiha - A. H. C. van Bruggen

Wageningen University, Biological Farming Systems

Group, Marijkeweg 22, 6709 PG Wageningen,

The Netherlands

N. A. S. Messiha - J. D. Janse

Department of Bacteriology, Plant Protection Service,

Geertjesweg 15, 6706 EA Wageningen, The Netherlands

N. A. S. Messiha

Potato Brown Rot Project (PBRP), 3 El-Amira Fatma

Ismail Street, Dokki, Cairo, Egypt

A. D. van Diepeningen

Laboratory of Genetics, Wageningen University,

Arboretumlaan 4, 6703 BD Wageningen, The Netherlands

N. S. Farag

Plant Pathology Research Institute(PPRI),

9 Gamaa Street, Giza, Cairo, Egypt

S. A. Abdallah

Faculty of Science, Department of Botany,

Benha University, Benha, Egypt

J. D. Janse $(\square)$

Department of Bacteriology, Plant protection service

(PD), P.O. Box 9102, 6700 HC Wageningen,

The Netherlands

e-mail: j.d.janse@minlnv.nl
$\mathrm{KB}$ agar medium and in vivo on potato plants. In vitro, four isolates of $S$. maltophilia (PD3531, PD3532, PD3533, and PD3534) appeared antagonistic. The isolate (PD3533) was screened as the most promising antagonist for the in vivo tests. In the greenhouse, the antagonist was applied directly to soil or by bacterization of potato eyepieces. Stenotrophomonas maltophilia significantly suppressed potato brown rot in Egyptian clay soil but not in Dutch clay soil. Survival of a rifampicin and chloramphenicol-resistant $S$. maltophilia strain PD4560 was investigated in two pairs of clay soils, conventionally and organically managed, from Egypt and the Netherlands. The survival of $S$. maltophilia was significantly less in Dutch than in Egyptian soils, while the converse occurred for $R$. solanacearum. These results are in agreement with those obtained in the in vivo biocontrol tests. In conclusion, S. maltophilia may be useful for control of brown rot in the area where it was originally isolated, the Nile Delta in Egypt.

Keywords Antibiotic resistance - Biological control · Clay soils · CMC carrier · Organic and conventional management $\cdot$ Survival

\section{Introduction}

Potato brown rot is a systemic bacterial wilt disease caused by Ralstonia solanacearum (Yabuuchi et al. 
1995). Ralstonia solanacearum is subdivided into five races on the basis of host range and five biovars on the basis of catabolic properties (Schaad 1988; Hayward 1991). The potato race 3 biovar 2, more recently also typed on the basis of genetic sequencing as Phylotype II, sequevar 1 (Prior and Fegan 2005), is the dominant race in both Egypt and Europe. Potato losses up to $75 \%$ due to the bacterial wilt have been recorded in many countries (Cook and Sequeira 1994).

Potato is one of the most important vegetable crops in Egypt, both for local consumption and for export. Brown rot was first recorded in Egypt by Briton-Jones (1925) in the Nile Delta area, based on symptoms only. The disease became endemic after the second world war, being serious along the river Nile from the 1970s onwards. The pathogen has also been found in irrigation water (Mickail et al. 1974; Mickail et al. 1985; Farag et al. 1999). Poor drainage and consequently high soil moisture levels in the heavy textured soils were associated with the high disease incidence in this area (Mickail et al. 1985). As potato brown rot was declared a quarantine disease of concern in the EU, Egypt moved the main potato production area to the virgin desert adjacent to the traditional agricultural lands, because these areas were still free from $R$. solanacearum.

Since 1989, potato brown rot was also observed in several north-western EU countries, where clear links were established with surface water contamination in almost all cases. It was first found in the Netherlands in 1992 in an isolated case and again in 1995, more widespread due to contaminations via irrigation water. An intensive programme for eradication was started and control measures taken according to European legislation, EC Control Directive 98/57/EC (Janse 1996; Janse et al. 1998; Schans and Steeghs 1998).

Control of potato brown rot has proven to be a serious, very difficult and puzzling task. Some resistant cultivars are available but these are not adapted to different agro-ecological zones and are not effective against all strains of the pathogen (Hartman and Elphinstone 1994; Mendoza 1994; Lopez and Biosca 2004). Breeding for disease tolerance is not desirable because of a possible correlation between the earliness of a cultivar and low disease tolerance (Farag 1970, 1976). Tolerant varieties could harbour virulent bacteria in a latent form (Priou et al. 1999). Chemical control by soil fumigants, antibiotics, and copper compounds was tried without much success (Farag et al. 1982; Hartman and Elphinstone 1994; Murakoshi and Takahashi 1984). In addition, most chemical pesticides have hazardous effects on the environment, non-target beneficial organisms and human health. Therefore, cultural and biological control of bacterial diseases was tried by many investigators as an alternative solution with some promising success (Michel and Mew 1998; Ran et al. 2005a, b; Rhodes and Logan 1987; Xu and Gross 1986a, b).

Ralstonia solanacearum race 3 , biovar 2 can survive in latently infected potato tubers, volunteer potatoes, tomatoes and weed hosts (such as woody nightshade, Solanum dulcamara), but also in soil for one to several years (Graham et al. 1979; van Elsas et al. 2000) and a number of weeks in surface water, depending on temperature (Janse et al. 1998; van Elsas et al. 2001). Thus, the most commonly recommended cultural practices to control potato brown rot are: use long crop rotations with non-hosts, do not use surface water for irrigation if possible, remove susceptible weeds, and only use healthy, tested seed tubers. In addition, fertilization practices can be adjusted so that the $\mathrm{pH}$ is $<5$ or $>8$ (Michel and Mew 1998; Sturz et al. 2004), provided that the crop can tolerate this. Application of certain composted animal manures or pig slurry can also reduce $R$. solanacearum populations and bacterial wilt disease of tomato and potato (Gorissen et al. 2004; Islam and Toyota 2004). Similarly, amendment of organically-managed soils with cow manure can reduce survival of $R$. solanacearum in soil and suppress brown rot development on potato plants (Messiha et al. unpublished). One of the mechanisms of disease suppression by manure or slurry may be a shift in microbial community towards greater antagonism against $R$. solanacearum (Gorissen et al. 2004; Messiha et al. unpublished). Repeated applications of organic materials like manure or compost can ultimately result in higher substrate availability for competitors, reduced growth of the pathogen in the rhizosphere, and reduced infection (Hoitink and Boehm 1999; Satoh and Toyota 2004). Thus, soil amendment with manure or compost may in fact be an indirect way of stimulating biological control.

Apart from indirect biological control, limited research has been carried out to find directly applicable biocontrol agents for management of bacterial 
wilt. Microorganisms which are able to grow in the rhizosphere are ideal for controlling root-borne pathogens (Bapat and Shah 2000; Ran et al. 2005b). Brown rot infection was reduced significantly after bacterization of healthy seed potatoes with Bacillus cereus, B. subtilis and with an avirulent strain of $R$. solanacearum under field conditions (Sunaina et al. 1997; Wagih 1991). Pseudomonas fluorescens was highly effective in reducing bacterial wilt in tomato and potato under experimental conditions by aggressively colonizing the roots of young plants and preventing entry of $R$. solanacearum (Aspiras and De-la Cruz 1986). Pseudomonas fluorescens was less effective at controlling bacterial wilt of Eucalyptus trees (Ran et al. 2005b). Inhibition of the pathogen by $P$. fluorescens was attributed to the siderophore pseudobactin, depriving root-colonizing microorganisms, including plant pathogens, of $\mathrm{Fe}^{3+}$ and inducing systemic resistance (Buyer and Leong 1986; Ran et al. 2005a, b).

Stenotrophomonas maltophilia is a common microorganism in the rhizosphere of cruciferous plants, and has also been found in association with corn and beets (Debette and Blondeau 1980). Excretion of sulphur-containing amino acids such as methionine by roots of cruciferous plants may favour the growth of this species. However, S. maltophilia is also quite dominant in the rhizosphere of cereal crops (Lambert and Joos 1989). Stenotrophomonas maltophilia can even colonize and persist inside tissues of potato plants (Garbeva et al. 2001). However, $S$. maltophilia has not been evaluated yet for its potential to control potato brown rot. However, it was proven to be an effective biocontrol agent for the control of various fungal and oomycetous plant pathogens (Berg et al. 2005; Dal Bello et al. 2002; Dunne et al. 1997; Nakayama et al. 1999; Zhang and Yuen 1999). Stenotrophomonas maltophilia inhibited the growth of Rhizoctonia solani and Verticillium dahliae in vitro, possibly as a result of antibiosis and production of lytic enzymes (Berg et al. 1996). Three antifungal compounds, designated xanthobaccins A, $\mathrm{B}$ and $\mathrm{C}$ were isolated from the culture filtrate of a strain of Stenotrophomonas isolated from sugar beet that suppressed damping-off of beet seedlings caused by Pythium spp. (Nakayama et al. 1999). Xanthobaccins were in vitro not effective against three bacterial species ( $R$. solanacearum was not included) (Nakayama et al. 1999). Stenotrophomonas maltophilia can take up iron (to a limited extent) from the siderophore pseudobactin (Jurkevitch et al. 1992), but it is unknown if it produces a siderophore.

This research was undertaken to investigate the antagonistic potential of $S$. maltophilia against $R$. solanacearum under laboratory and greenhouse conditions. Survival of the antagonist was tested in two pairs of clay soils, conventional and organic from Egyptian and Dutch origins.

\section{Materials and methods}

Isolation of antagonists and in vitro inhibition bioassay

Selection of potential antagonists was made from rhizosphere soils of eggplant (Solanum melongena Black Beauty) and sweet pepper (Capsicum annuum) at the late fruiting stage from two locations of vegetable growing areas in Kafr El-zayat, Gharbia governorate, Delta, Egypt. Soil was gently shaken from the roots, and remaining soil plus roots were considered as rhizosphere soil. About $1 \mathrm{~g}$ of rhizosphere soil was sampled and suspended in sterile phosphate buffer (PB $0.05 \mathrm{M}: \mathrm{Na}_{2} \mathrm{HPO}_{4} \cdot 12 \mathrm{H}_{2} \mathrm{O}$, $4.26 \mathrm{~g} ; \mathrm{KH}_{2} \mathrm{PO}_{4}, 2.72 \mathrm{~g} ; 11$ distilled water; $\mathrm{pH}$ 7.2). Samples were shaken for $1 \mathrm{~h}$. Six serial 10 -fold dilutions were made for each sample and spread on soil extract agar media (SEA: glucose, $1 \mathrm{~g} ; \mathrm{K}_{2} \mathrm{HPO}_{4}$, $0.5 \mathrm{~g}$; yeast extract, $1.5 \mathrm{~g}$; soil extract $(1 \mathrm{~kg}$ in 11 water), $500 \mathrm{ml}$; agar, $20 \mathrm{~g}$; tap water, $500 \mathrm{ml}$; $\mathrm{pH} 7.2$ ) (Allen 1957). Colonies developed on isolation plates were washed with sterile water ( $2 \mathrm{ml} /$ isolate), purified, and streaked over the middle of the surface of King's B agar plates (KB: proteose peptone, $20 \mathrm{~g}$; $\mathrm{K}_{2} \mathrm{HPO}_{4}, 1.5 \mathrm{~g}$; $\mathrm{MgSO}_{4}, 1.5 \mathrm{~g}$; agar, $20 \mathrm{~g}$; glycerol, $15 \mathrm{ml}$; distilled water; $1000 \mathrm{ml}$ ). Plates were incubated at $28^{\circ} \mathrm{C}$ for $48 \mathrm{~h}$. A mixture of three previously identified $R$. solanacearum strains isolated from potato tubers in Egypt (marked as PD5239, PD5240 and PD5241 in the culture collection of the Plant Protection Service, Wageningen, the Netherlands) was streaked in six lines, perpendicular to the antagonist streak, and incubated again at $28^{\circ} \mathrm{C}$ for 48 h. The distance free from $R$. solanacearum, near the antagonist line was determined. In another trial both the antagonist and the pathogen were streaked parallel to each other, $0.5 \mathrm{~cm}$ apart, then incubated 
side by side and the plates were kept under the same conditions. The absence of $R$. solanacearum growth was scored positive for suppression by the antagonist.

In a third trial, ferric ions were incorporated in King's B medium in the form of ferric sulphate $\left[\mathrm{Fe}_{2}\right.$ $\left(\mathrm{SO}_{4}\right)_{3} \cdot \mathrm{H}_{2} \mathrm{O}$ ] with a final concentration of $100 \mu \mathrm{M}$ of $\mathrm{Fe}^{+3}$. KB medium plates without supplemental iron served as controls. One hundred $\mu \mathrm{l}$ of a S. maltophilia suspension $\left(10^{9} \mathrm{CFU} \mathrm{ml} \mathrm{m}^{-1}\right)$ was spread onto the plates to determine the effect of iron availability on the antagonistic potential of $S$. maltophilia. A similar suspension of an antagonistic P. fluorescens strain (PD3340), spread onto iron-amended and nonamended plates, served as the control.

Identification of the antagonist

Whole cell fatty acid methyl esters (FAME) were prepared according to standard protocols (Janse 1991; Stead 1992), and fatty acid analysis (FAA) was carried out using a gas chromatograph coupled to the Microbial Identification System with a commercially available database and software (MIDI, Newark DE 19711, USA). The method is briefly described in the following paragraph.

Four antagonistic bacterial isolates were grown on trypticase soy broth agar (TSBA) at $28^{\circ} \mathrm{C}$ for $24 \mathrm{~h}$ and harvested in glass tubes. For saponification, $1 \mathrm{ml}$ of reagent $1(\mathrm{NaOH}, 45 \mathrm{~g}$; methanol, $150 \mathrm{ml}$; distilled water $150 \mathrm{ml}$ ) was added to each sample and heated in a water bath for $30 \mathrm{~min}$. For methylation, $2 \mathrm{ml}$ of reagent 2 (certified $6.0 \mathrm{~N} \mathrm{HCl}, 325 \mathrm{ml}$; methanol, $275 \mathrm{ml}$ ) was added to the cooled tubes and heated for $10 \pm 1$ min at $80 \pm 1{ }^{\circ} \mathrm{C}$, dropping the $\mathrm{pH}$ below 1.5. FAME were extracted in $1.25 \mathrm{ml}$ of organic solvent (reagent 3: $200 \mathrm{ml}$; methyl tetra-butyl ether, $200 \mathrm{ml}$ ) per cooled tube. The aqueous phase was removed by pipette and the organic phase was washed with $3 \mathrm{ml}$ of reagent $4(\mathrm{NaOH}, 10.8 \mathrm{~g}$; distilled water $9000 \mathrm{ml})$ to reduce contamination of the injection port liner, the column, and of the detector of the gas chromatograph. A standard calibration mixture (MIDI) was used, consisting of straight chain saturated fatty acids from 9 to 20 carbons in length (9:0 to 20:0), with five hydroxy fatty acids. All bacterial strains were identified based on a comparison of the fatty acid compositions with those in the database of the MIDI system (TSBA).
The strains were also physiologically and biochemically characterized according to Bergey's Manual of Systematic Bacteriology (Holt et al. 1994) to confirm the results of FAA. The following tests were carried out: Gram-staining, motility, oxidative/fermentative metabolism of glucose $(\mathrm{O} / \mathrm{F})$, gelatine hydrolysis, levan formation from on $5 \%$ sucrose agar utilization of $\mathrm{H}_{2} \mathrm{~S}$, utilization of nitrate as nitrogen source, acid production from $\mathrm{D}$-glucose, trehalose and inositol (1\%) in peptone-free basal medium with bromothymol blue (Dowson 1957). The media were inoculated at a density of $10^{6}$ bacteria $\mathrm{ml}^{-1}$, and incubated at $28^{\circ} \mathrm{C}$ for 14 days. Acid production from the three sugars was recorded at 3-day intervals. A colour change from green to yellow was considered positive.

Suppression of $R$. solanacearum and brown rot control

Biological control potential of S. maltophilia against $R$. solanacearum was evaluated under greenhouse conditions for Egyptian and Dutch soils separately. Conventionally managed clay soil was used in Egypt, while both conventionally and organically managed clay soil was used in the Netherlands. Two potato cultivars were used: medium-early maturing diseasesusceptible cv. Nicola and medium-late maturing moderately tolerant cv. Diamant. Potato eyepieces were immersed for $5 \mathrm{~min}$ in $0.05 \%$ (aq.) $\mathrm{NaOCl}$, washed 5 times in sterile distilled water, and air dried for $48 \mathrm{~h}$. Soil was infested with a mixture of three virulent Egyptian strains of race 3 biovar 2 of $R$. solanacearum: PD5239, PD5240 and PD5241 (culture collection, Plant Protection Service, Wageningen, the Netherlands). The bacterial strains were grown for $48 \mathrm{~h}$ on nutrient agar (NA) plates at $28^{\circ} \mathrm{C}$. The bacterial cultures were suspended in $0.01 \mathrm{M}$ phosphate buffer (PB) and the bacterial density was adjusted to $5 \times 10^{9} \mathrm{CFU} \mathrm{ml} \mathrm{m}^{-1}$ using a spectrophotometer. The inoculum was mixed with the soil to have a final bacterial concentration of $10^{7} \mathrm{CFU} \mathrm{\textrm {g } ^ { - 1 }}$ dry soils.

One strain of S. maltophilia (PD3533) that could use nitrate as nitrogen source was selected for the biocontrol tests, as potato brown rot is especially severe in soils containing high nitrate concentrations (Messiha et al. unpublished). The antagonist was applied both by soil inoculation and bacterization of potato eyepieces. Stenotrophomonas maltophilia was 
propagated in trypticase soy broth (TSB) and incubated for $18 \mathrm{~h}$ (logarithmic phase) at $28^{\circ} \mathrm{C}$. The bacteria were harvested by centrifugation, washed with sterile distilled water, centrifuged again and re-suspended in water to the required concentration (Campbell et al. 1986). The inoculation suspension was adjusted to give $10^{8} \mathrm{CFU} \mathrm{g^{-1 }}$ soil (CiampiPanno et al. 1989). For bacterization of eyepieces, the antagonist was resuspended in sterile $1 \%$ carboxymethyl cellulose (CMC) at $10^{10} \mathrm{CFU} \mathrm{ml}^{-1}$ (Bapat and Shah 2000). Eyepieces were immersed in the bacterial suspension in CMC for $15 \mathrm{~min}$ and left to dry for two days before planting. The conditions of the greenhouse were adjusted to $25^{\circ} \mathrm{C}$ during the day and $20^{\circ} \mathrm{C}$ during the night, with a $\mathrm{RH}$ of 75 to $80 \%$ and a total of $14 \mathrm{~h}$ light. Three experiments were conducted.

\section{Experiment 1}

Non-sterilized Egyptian conventional clay soil was used for this experiment. Stenotrophomonas maltophilia was applied by soil inoculation or by bacterization of the eyepieces of potato cv. Nicola and cv. Diamant. Soil inoculated with the pathogen only was added to 48 pots (5 $\mathrm{kg}$ each), 24 planted with nontreated potato eye pieces and 24 planted with eye pieces treated with $S$. maltophilia. Soil inoculated with the pathogen and antagonist was added to 24 pots, and non-inoculated soil to 6 pots as negative controls. Two eyepieces of either of the potato cultivars (with or without S. maltophilia) were planted in each of 12 pots (replications). The 78 pots were placed on a greenhouse bench in a completely randomized design. Potted plants were not fertilized since the soil came from fertilized potato fields. Plants were carefully irrigated overhead to prevent splashing. The $\%$ infected plants was determined 90 days after planting. Rhizosphere samples were collected from each pot as mentioned above. Three ten-fold serial dilutions were made from each sample and $100 \mu \mathrm{l}$ was plated onto Selective Media South Africa (SMSA) (Anon. 1998). Latent infection in the lower stem area (crown area) of each plant was checked by plating $5-\mathrm{cm}$ long, weighed sections of surface-sterilized and macerated plant tissues on SMSA plates. Maceration by mortar and pestle was done in phosphate buffer saline (PBS $0.01 \mathrm{M}$ ), $\left(\mathrm{Na}_{2} \mathrm{HPO}_{4} \cdot 12 \mathrm{H}_{2} \mathrm{O}, 2.7 \mathrm{~g} ; \mathrm{NaH}_{2} \mathrm{PO}_{4} \cdot 2 \mathrm{H}_{2} \mathrm{O}, 0.4 \mathrm{~g}\right.$;
$\mathrm{NaCl}, 8 \mathrm{~g} ; 11$ distilled water; $\mathrm{pH}$ 7.2), and the extract was left for $1 \mathrm{~h}$. About $1 \%$ of all colonies with a morphology typical for $R$. solanacearum (colony with irregular shape, diffuse white or purple centres and luxuriant slime) were randomly selected and tested using Immunofluorescence Antibody Staining, IFAS, (Janse 1988). The number of $R$. solanacearum CFU $\mathrm{g}^{-1}$ dry rhizosphere soil was calculated.

\section{Experiment 2}

Eyepieces of cv. Diamant were planted in nonsterilized and sterilized Egyptian conventional clay soil. The pathogen was mixed into soil as mentioned before, keeping some of the soil non-inoculated. The antagonist was applied by eyepiece bacterization only; half of the eyepieces remained non-treated. There were $2 \times 2=4$ treatments with 20 replications (pots of $5 \mathrm{~kg}$ ) each in a completely randomized design. All 80 pots contained soil with $R$. solanacearum; in addition, there were four negative control pots without the pathogen. No fertilizer was added, and overhead irrigation was carefully applied. Wilt development was scored after 60,75 and 85 days. A 0-5 scoring scale was used: $0=$ no symptoms, $1=$ 1-2 leaves wilted per plant (about 20\%), $2=3-4$ leaves wilted per plant (about 50\%), $3=$ most of the leaves wilted (about 80\%), $4=$ all leaves wilted, and $5=$ plant dead. A wilt index was calculated as the sum of the [number of plants in each category $\times$ category number]. Before carrying out $\chi^{2}$-tests, plants in the categories 1,2 and 3 were combined and the categories 4 and 5 were combined, so that the following classes resulted: $0=$ no symptoms, $1=$ slight to severe wilt, and $2=$ completely wilted or dead. Visible and latent infections by $R$. solanaceearum were tested at the end of the experiment (after 85 days), by plating surface-sterilized and macerated stem sections on SMSA as mentioned above. The identity of putative $R$. solanacearum colonies was confirmed by IFAS. The experiment was conducted twice.

\section{Experiment 3}

Eyepieces of cv. Nicola were planted in non-sterilized Dutch conventional and organic clay soil. The pathogen and the antagonist were applied as in experiment 2 , resulting again in 4 treatments. Instead 
of pots, trays were used, containing $5 \mathrm{~kg}$ of soil. Eight eyepieces were planted per tray. There were 4 trays (replications) per treatment, plus 4 trays with noninoculated soil as negative controls. Wilt incidence and severity were observed daily for 45 days as described under experiment 2. Latent infection was tested by making isolations from the crown areas of each plant onto SMSA plates. The experiment was carried out twice.

Survival of S. maltophilia in soil and its effect on survival of $R$. solanacearum

A spontaneous rifampicin and chloramphenicol-resistant mutant of $S$. maltophilia strain PD3533 was selected and adapted in the laboratory for testing its survival in different soils. The strain was selected from the wild-type strain by growing it in TSBA amended with increasing concentrations of rifampicin and chloramphenicol $(0,20,40,60,80$ and $100 \mu \mathrm{g} \mathrm{ml}^{-1}$ for each antibiotic). The antibioticresistant strain (PD4560) was subjected again to FAA to confirm its identity as S. maltophilia, and was tested in vitro for antagonistic potential against $R$. solanacearum. The same strain mixture of $R$. solanacearum was used as in the previous experiment.

Two pairs of clay soil, half from organically managed arable farms and the other half from conventionally managed arable farms were used in this study. One pair originated from Egypt, the other was from the Netherlands (Table 1). The soils were the same as those used in the greenhouse experiments. The antibiotic resistant $S$. maltophilia was grown for $48 \mathrm{~h}$ on trypticase soy broth agar (TSBA) plates at $28^{\circ} \mathrm{C}$, and $R$. solanacearum was grown on NA plates under the same conditions. The bacterial cultures were suspended in $0.01 \mathrm{M}$ phosphate buffer (PB) separately. Suspensions of $R$. solanacearum, S. maltophilia or both were mixed with $100 \mathrm{~g}$ of each soil in plastic bags so that a final concentration of $5 \times 10^{7} \mathrm{CFU} \mathrm{g}^{-1}$ dry soil was attained for each strain. Inoculated samples were divided over five 50-ml Greiner tubes with loosely closed lids to allow air exchange, and incubated at $28^{\circ} \mathrm{C}$. The moisture content was $22.6 \%$ of the soil fresh weight, water loss was checked weekly and any lost water was replaced to keep a constant moisture level. Both the pathogen and antagonist populations were monitored in all treatments twice a week for the first two weeks, starting at the day of inoculation $\left(\mathrm{T}_{0}\right)$, once a week for the next two weeks and then once a month for a total of five months until the pathogen population was below the detection limit (100 CFU $\mathrm{g}^{-1}$ dry soil) in all soils.

For bacterial counts, 1-g samples of the soils (1 sample per soil replicate) were suspended in $9 \mathrm{ml}$ of sterile $0.05 \mathrm{M}$ phosphate buffer. After shaking at $100 \mathrm{rev} \min ^{-1}$ for $2 \mathrm{~h}$ at $20^{\circ} \mathrm{C}, 10$-fold serial dilutions

Table 1 Physical, chemical and biological composition of the different soils

\begin{tabular}{|c|c|c|c|c|c|c|c|c|c|c|c|c|c|}
\hline \multirow[t]{2}{*}{$\begin{array}{l}\text { Soil } \\
\text { code }^{c}\end{array}$} & \multirow[t]{2}{*}{ Country } & \multirow[t]{2}{*}{ Management } & \multirow[t]{2}{*}{ Location } & \multicolumn{4}{|c|}{ Soil composition $^{\mathrm{a}}$} & \multicolumn{4}{|c|}{ Nutrients $\mathrm{mg} \mathrm{kg}^{-1}$} & \multicolumn{2}{|c|}{$\begin{array}{l}\text { Diversity } \\
\text { index }^{b}\end{array}$} \\
\hline & & & & Clay $(\%)$ & $\operatorname{Silt}(\%)$ & Sand $(\%)$ & $\mathrm{OM}(\%)$ & $\mathrm{TOC}^{\mathrm{d}}$ & $\begin{array}{l}\mathrm{N}- \\
\mathrm{NO}_{3}\end{array}$ & $\begin{array}{l}\mathrm{N}- \\
\mathrm{NH}_{4}\end{array}$ & $\begin{array}{l}\mathrm{pH}- \\
\mathrm{KCl}\end{array}$ & $S$ & $H^{\prime}$ \\
\hline ECC & Egypt & Conventional & $\begin{array}{l}\text { Behera, Delta } \\
\text { area }\end{array}$ & 9.4 & 54.5 & 36.1 & 4.9 & 133.2 & 128 & 19.2 & 7.6 & 21.3 & 1.23 \\
\hline ECO & Egypt & Organic & $\begin{array}{l}\text { Kaliobia, Delta } \\
\text { area }\end{array}$ & 13.9 & 65.7 & 20.4 & 6.2 & 079.9 & 62 & 16.3 & 7.6 & 18.3 & 1.19 \\
\hline $\mathrm{NCC}$ & NL & Conventional & $\begin{array}{l}\text { Ens, Northeast } \\
\text { polder }\end{array}$ & 7.7 & 51.9 & 40.4 & 2.2 & 122.1 & 10 & 13.9 & 7.4 & 18.8 & 1.11 \\
\hline $\mathrm{NCO}$ & NL & Organic & $\begin{array}{l}\text { Ens, Northeast } \\
\text { polder }\end{array}$ & 8.3 & 54.5 & 37.2 & 2.3 & 125.7 & 7 & 15.8 & 7.3 & 24.5 & 1.13 \\
\hline
\end{tabular}

\footnotetext{
a Particles size: clay $<2 \mu \mathrm{m}$, silt 2-50 $\mu \mathrm{m}$, sand 50-2000 $\mu \mathrm{m}$.

b Average species richness $S$ and Shannon-Wiener diversity index $H^{\prime}$

c First letter stands for country of origin (Egypt or the Netherlands), Second for soil type (clay) and third for management (conventional or organic)

d Total soluble organic carbon
} 
were made, and spread on 3 plates each of TSBA amended with $100 \mathrm{mg}$ chloramphenicol and $100 \mathrm{mg}$ rifampicin $1^{-1}$ for $S$. maltophilia detection and on SMSA plates for $R$. solanacearum detection. Stenotrophomonas maltophilia colonies were counted after 3 days and $R$. solanacearum colonies after 5-7 days of incubation at $28^{\circ} \mathrm{C}$. IFAS was used to confirm putative colonies of the pathogen. The experiment was conducted twice.

\section{Soil analyses}

For physical and chemical analysis $100-\mathrm{g}$ samples of all soils were air-dried at room temperature. Soil textures were assessed in the Laboratory of Soil Science and Geology of Wageningen University (Table 1). Particle sizes of $<2 \mu \mathrm{m}$ were considered clay, 2-50 $\mu \mathrm{m}$ was considered silt and 50-2,000 $\mu \mathrm{m}$ was considered sand. Organic matter content was determined using the loss on ignition method according to Houba et al. (1997). Dissolved organic carbon (DOC), nitrate and ammonium content and $\mathrm{pH}$ were measured after Houba and Novozamsky (1998).

PCR and DGGE analysis

Duplicate soil samples used for PCR and DGGE were stored at $-20^{\circ} \mathrm{C}$. Total DNA was extracted from $0.5 \mathrm{~g}$ (wet weight) soil samples with the Bio101 FastDNA $^{\circledR}$ SPIN Kit for Soil, according to the manufacturer's specifications (Bio101, Carlsbad, CA, USA); a $20 \mathrm{~min}$ incubation time at $65^{\circ} \mathrm{C}$ was added to enhance the elution. For DGGE analysis of the eubacterial soil population, the V6 to V8 region of the 16S rRNA gene was amplified from total soil DNA with the primers $968 \mathrm{f}-\mathrm{GC}$ and $1401 \mathrm{r}$ (Heuer and Smalla 1997). Two nanogram of DNA was added to $50 \mu \mathrm{l}$ PCR reactions and amplified using a touchdown scheme (Hiddink et al. 2005).

DGGE was performed using the Dcode system (BIOrad Laboratories, Hercules, CA, USA) according to Hiddink et al. (2005). All samples were analyzed at least in duplicate. Gels were stained with BIOrad's Silver Stain (BIOrad Laboratories, Hercules, CA, USA), preserved in Cairn's preservation solution of $25 \%$ ethanol (v v-1) and $10 \%$ glycerol (v v-1), covered by a permeable cellophane sheet (Amersham Pharmacia Biotech Ag, Uppsala, Sweden) and dried overnight at $60^{\circ} \mathrm{C}$. The gels were than scanned using
ScanSoft Omnipage, programme 14 at a resolution of 300 dots inch $^{-1}$ and analyzed with Phoretix 1D (NonLinear Dynamics Ltd., Newcastle upon Tyne, UK), including only bands with pixel intensity $>1$.

Statistical analyses

To evaluate the disease incidence in the first two biocontrol experiments, $\chi^{2}$-tests were conducted on contingency tables with classes of number of plants infected or wilted versus the various treatments to be compared (soil origin, soil treatment and antagonist amendment) using Microsoft Excel 2003 (Microsoft Corporation, Seattle, WA, USA).

For the first experiment, ANOVA was conducted to compare the density of $R$. solanacearum in the rhizosphere for the two different cultivars and $S$. maltophilia treatments (control, soil amendment with the antagonist and bacterization of eyepieces with the antagonist). Interaction between cultivar and antagonist treatment was also determined. Fisher's LSD test was used to compare each pair of treatments. A $t$-test was conducted to compare the densities of $R$. solanacearum in the rhizosphere of the two different cultivars in the treatment without $S$. maltophilia. All analyses were conducted using SPSS v 12 (SPSS Inc., Chicago, Illinois, USA).

For the third experiment, areas under the disease progress curves (AUDPC) were calculated based on $\%$ leaves wilted per plant over time. Non-parametric Mann-Whitney tests were carried out on AUDPC and $\%$ stem pieces infected for the two management types (organic and conventional) and S. maltophilia treatments (inoculated and non-inoculated eyepieces).

Survival curves of the pathogen and the antagonist were fitted to CFUs over time as follows. Log (CFU $+1 / \mathrm{g}$ dry soil) was calculated for each sample. Log-transformed data (for each replicate, soil and treatment separately) were fitted to a logistic decay model as described by Franz et al. (2005):

$C_{\mathrm{t}}=a_{\mathrm{m}} /(1+\exp (-d *(t-c)))$

where $C_{\mathrm{t}}=\log$ transformed bacterial density, $a_{\mathrm{m}}=$ initial density, $d=$ decline rate $\left(\right.$ days $\left.^{-1}\right), t=$ time (days) and $c=$ length of the 50\%-reduction-time in days. The estimated parameter values $c$ and $d$ for the different soils were subjected to multivariate analysis of variance (MANOVA, using SPSS v 12, SPSS Inc., 
Chicago, Illinois, USA) to determine the effect of soil origin and management on the survival of $S$. maltophilia and $R$. solanacearum, and to detect the effect of $S$. maltophilia on the survival of $R$. solanacearum in different soils. Effects of different treatments on $c$ and $d$ separately for both the antagonist and the pathogen were tested with ANOVA.

The bacterial diversity in the soil samples was estimated in two ways: as species richness $S$ and as the Shannon-Wiener index of bacterial diversity, $H^{\prime}$. $S$ was determined by the number of detected DGGE bands per soil (van Diepeningen et al. 2006), and $H^{\prime}=-P i \log P i$ based on the relative band intensities as formulated by Eichner et al. (1999). $P i$ is defined as $n i / \mathrm{N}$ where $n i$ is the area of the peak in intensity and $\mathrm{N}$ the sum of all peak areas in the lane profile. Both biodiversity indices are given as averages with standard deviations based on multiple samples on replicate DGGE gels. A $t$-test was conducted to compare $S$ and $H^{\prime}$ from conventional versus organic soil for each country.

\section{Results}

Isolation and identification of the antagonists

Total bacterial densities in rhizosphere soil from eggplant were $3.5 \times 10^{7} \mathrm{cfu} \mathrm{g}^{-1}$ at the first and $1.8 \times 10^{7} \mathrm{cfu} \mathrm{g}^{-1}$ at the second location. Bacterial densities from sweet pepper rhizosphere soil were lower: $9.4 \times 10^{6} \mathrm{cfu} \mathrm{g}^{-1}$ and $2.4 \times 10^{7} \mathrm{cfu} \mathrm{g}^{-1}$, respectively. From the rhizosphere of eggplant, three out of sixteen $(18.8 \%)$ and one out of twenty-six $(3.8 \%)$ randomly selected colonies on the countable plates showed in vitro antagonistic properties against $R$. solanacearum from the first and second location, respectively. All four isolates showed a strong inhibition zone of about $9 \mathrm{~mm}$. The rhizosphere of pepper did not yield any antagonistic bacteria against the pathogen at similar dilutions.

For all four antagonistic strains, the majority of FAs were branched and were identified as C15:0 ISO, C15:0 ANTEISO, C16:1 $\omega 7 \mathrm{c} / 15$ ISO 2OH, C16:0 and C15:0 ISO 2OH/ 16: $1 \omega 7 \mathrm{c}$. Three isolates (PD3531, PD3533, and PD3534) were identified as Stenotrophomonas maltophilia (Hugh 1981) (previously known as Pseudomonas maltophilia, then Xanthomonas maltophilia), with a high degree of similarity
(>79\%) to the reference strain, while PD3532 showed only $41 \%$ of similarity to the S. maltophilia reference strain using the TSBA database of the MIDI system.

All four strains produced a non-diffusible yellow colour on TSBA medium, and were aerobic Gramnegative, motile rods. All isolates were able to liquefy gelatine, produced acid from D-glucose and trehalose, and produced $\mathrm{H}_{2} \mathrm{~S}$. Only PD 3533 and PD 3534 were able to use nitrate as the nitrogen source. All isolates were negative for arginine dihydrolase production, and were unable to form levan on $5 \%$ sucrose agar and acid from inositol. The results of the biochemical and physiological tests were in agreement with Holt et al. (1994) and with the FAA identification.

The four S. maltophilia isolates from eggplant rhizospheres were tested for their ability to suppress $R$. solanacearum in the absence and presence of $100 \mu \mathrm{M} \mathrm{Fe}^{+3}$ in the medium. The additional iron did not affect the antagonistic effect of S. maltophilia, while that of $P$. fluorescens disappeared on ironamended media (data not shown).

Suppression of $R$. solanacearum and brown rot control

\section{Experiment 1}

There was a significant interaction $(P=0.001)$ between $S$. maltophilia treatment and cultivar with respect to disease development in $R$. solanacearuminoculated soil. Potato plants in non-inoculated soil remained healthy. The \% plants infected by $R$. solanacearum was higher for Nicola compared to Diamant in the control treatment without S. maltophilia $(100 \%$ and $58.3 \%$, respectively; $P=0.012$ ). For Nicola, inoculation of soil or eyepieces with $S$. maltophilia decreased $\%$ infected plants from $100 \%$ to $25 \%$ or $16.7 \%(P<0.001)$ in the case of soil or eyepiece amendment, respectively. For Diamant, inoculation with S. maltophilia decreased \% infected plants from $58.3 \%$ to $16.7 \%(P<0.001)$ in the case of soil amendment, and to $25 \%(P=0.008)$ in the case of eyepiece inoculation (Fig. 1).

There was also a significant interaction $(P=0.004)$ in the cultivar $\times S$. maltophilia treatment with respect to density of $R$. solanacearum in the rhizosphere of potato plants grown in inoculated soil. No significant difference in pathogen density was found between the 


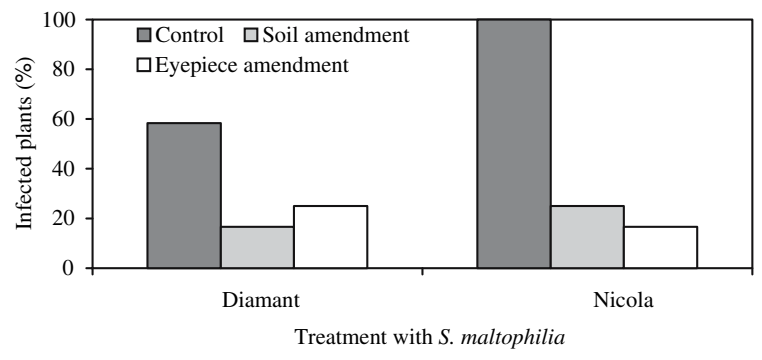

Fig. 1 Effect of soil amendment and eyepiece treatment with $S$. maltophilia on \% potato plants infected by $R$. solanacearum 90 days after planting, for the medium-late, brown rot tolerant cv. Diamant and the early, susceptible cv. Nicola

two cultivars grown without $S$. maltophilia. For Nicola, application of $S$. maltophilia significantly decreased the pathogen density from $2.0 \times 10^{5} \mathrm{~g}^{-1}$ in the non-amended control to undetectable levels for both $S$. maltophilia treatments $(P<0.001)$. For Diamant, application of $S$. maltophilia decreased the pathogen density from $2.3 \times 10^{5} \mathrm{~g}^{-1}$ to $2.2 \times 10^{5} \mathrm{~g}^{-1}$ in the case of soil amendment (not significant) and to an undetectable level in the case of eyepiece amendment $(P=0.002)$.

\section{Experiment 2}

Wilt incidence was higher in sterilized soil compared to non-sterilized soil at all three sampling times: the $\chi^{2}$-value was $13.89(P<0.001), 8.72(P<0.01)$, and $15.09(P<0.001)$ at 60,75 , and 85 days, respectively. The $\%$ infection at the end of the experiment was also significantly higher in sterilized than in non-sterilized soil $(P=0.03)$. For sterilized soil, wilt incidence was significantly less in antagonist-amended soil compared to non-amended soil at the three time intervals: the $\chi^{2}$ value was $12.73,20.83$, and $13.36(P<0.001)$ for 60,75 and 85 days, respectively. There was $50 \%$ reduction in $\%$ infected plants in antagonist-amended soil compared to non-amended soil $(P=0.002)$ (Table 2). In non-sterilized soil, wilt incidence was also significantly lower in antagonist-amended than in non-amended soil, but only 85 days after planting $\left(\chi^{2}=11.51, P<0.001\right)$. There was $36.4 \%$ reduction in $\%$ infected plants in antagonist-amended soil compared to non-amended non-sterilized soil $(P=0.015)$ (Table 2).

\section{Experiment 3}

Disease incidence and severity were generally low in the non-sterilized Dutch clay soils. On average, $37.5 \%$ plants were infected and $12.5 \%$ wilted 45 days after planting. No significant differences were found in wilt incidence and \% infection between conventional versus organic, or between $S$. maltophilia amended and non-amended soil (Data not shown).

Survival of S. maltophilia in soil and its effect on survival of $R$. solanacearum

Survival of S. maltophilia was significantly higher in Egyptian soils compared to Dutch soils (Fig. 2),

Table 2 Effect of application of S. maltophilia on wilt development of potato caused by Ralstonia solanacearum race 3 biovar 2 in sterilized and non-sterilized Egyptian conventionally managed clay soil ${ }^{\text {a }}$

\begin{tabular}{|c|c|c|c|c|c|}
\hline \multirow[b]{2}{*}{ Inoculation treatment } & \multirow[b]{2}{*}{ Soil treatment } & \multicolumn{3}{|c|}{ Days after planting } & \multirow{2}{*}{$\begin{array}{l}\mathrm{IF}^{\mathrm{b}} \\
(\%)\end{array}$} \\
\hline & & 60 & 75 & 85 & \\
\hline \multirow[t]{2}{*}{ Control } & Sterilized & 0 & 0 & 0 & 0 \\
\hline & Non-sterilized & 0 & 0 & 0 & 0 \\
\hline \multirow[t]{2}{*}{ Sterilized } & R. solanacearum & 10.0 & 22.0 & 46.4 & 70 \\
\hline & $R$. solanacearum $+S$. maltophilia & 0 & 0 & 6.3 & 35 \\
\hline$\chi^{2}$ & & 12.7 & 20.8 & 13.4 & 10.4 \\
\hline \multirow[t]{2}{*}{ Non-sterilized } & R. solanacearum & 0 & 6.5 & 13.3 & 55 \\
\hline & $R$. solanacearum $+S$. maltophilia & 0 & 0 & 0 & 35 \\
\hline$\chi^{2}$ & & 0 & 0.6 & 11.5 & 5.4 \\
\hline
\end{tabular}




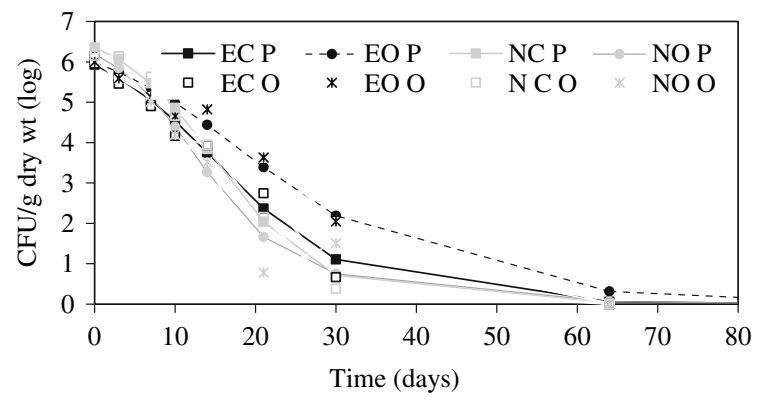

Fig. 2 Decline in density (CFU g ${ }^{-1}$ dry soil) of $S$. maltophilia in different soil types with different management regimes at $28^{\circ} \mathrm{C}$. The dots are the observed values. The lines are the predicted values from the logistic decline model: $C_{\mathrm{t}}=a_{\mathrm{m}}$ / $\left(1+\exp \left(-d^{*}(t-c)\right)\right)$. Where $C_{\mathrm{t}}=\log$ transformed number of bacteria, $a_{\mathrm{m}}=$ initial density of the pathogen, $d=$ decline rate (days $^{-1}$ ), and $t=$ time (days) and $c=$ length of the $50 \%$ reduction-time in days (Franz et al. 2005). The first letter represents country, $\mathrm{E}=$ Egypt, $\mathrm{N}=\mathrm{NL}$; the second letter represents management, $\mathrm{C}=$ conventional, $\mathrm{O}=$ organic; and the last letter represents the type of values, $\mathrm{P}=$ predicted and $\mathrm{O}=$ observed values

MANOVA: Wilk's Lambda $=0.075, P=0.021$, ANOVA for the 50\%-reduction-time (c): $F=5.2$, $P=0.084$ while for the decline rate (d): $F=34.3$, $P=0.004$. No significant difference in survival of $S$. maltophilia was found between the different management types for soils from both countries. Soil $\mathrm{pH}$ and organic matter content (OM) were both positively correlated to survival of $S$. maltophilia: for $\mathrm{pH}$, $r=0.965(P=0.035)$ for $c$ and $r=0.968(P=0.032)$ for $d$; for OM, $r=0.855(P=0.146)$ for $c$ and $r=0.953(P=0.047)$ for $d$. There were no significant correlations with other soil characteristics.

Contrary to $S$. maltophilia, survival of $R$. solanacearum was significantly higher in Dutch soils than in Egyptian soils (Fig. 3), MANOVA: Wilk's Lambda $=0.46, P=0.003$, ANOVA for the $50 \%$ reduction-time (c): $F=8.92, P=0.009$ while for the decline rate $(\mathrm{d}): \mathrm{F}=18.16, P=0.001$. The pathogen generally survived longer in conventional than in organic soils, especially in the Dutch soils. For Egyptian soils, the difference between organic and conventional management was due to a higher decline rate in the organic soil (MANOVA: Wilk's Lambda $=0.03, P=0.005$, ANOVA for the 50\%-reduction-time (c): $F=1.88, P=0.243$; for the decline rate $(\mathrm{d}): F=19.02, P<0.001)$. For Dutch soils, the difference was due to a shorter
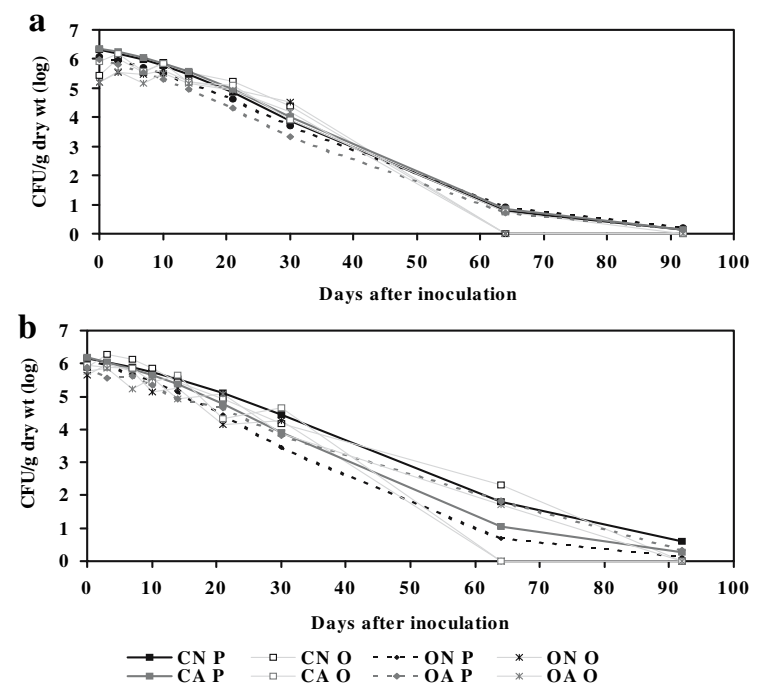

Fig. 3 The effects soil amendment with S. maltophilia on the decline of $R$. solanacearum at $28^{\circ} \mathrm{C}\left(\mathrm{CFU} \mathrm{g}{ }^{-1}\right.$ dry soil): (a) soil from Egypt and (b) soil from the Netherlands. The first letter represents management, $\mathrm{C}=$ conventional, $\mathrm{O}=$ organic; the second letter represents amendment, $\mathrm{N}=$ non-amended, $\mathrm{a}=$ Amended with $S$. maltophilia, and $\mathrm{P}=$ predicted values and $\mathrm{O}=$ observed values

50\%-reduction-time and a higher decline rate in the organic soil (MANOVA: Wilk's Lambda $=0.10$, $P=0.032$, ANOVA for the $50 \%$-reduction-time (c): $F=34.15, P=0.004$; and for the decline rate $(\mathrm{d})$ : $F=26.56, P=0.007)$. There were negative correlations between the survival of $R$. solanacearum and $\mathrm{NO}_{3}(r=-0.86, P=0.069 ; r=-0.88$, $P=0.060$, for 50\%-reduction-time and decline phase, respectively) and $\mathrm{pH}(r=-0.95, P=0.025$; $r=-0.96, P=0.019$, respectively).

Amendment of conventional soils from both countries with $S$. maltophilia did not affect the survival of $R$. solanacaerum. Amendment of Egyptian organic soil with $S$. maltophilia suppressed the survival of $R$. solanacearum, MANOVA: Wilk's Lambda $=0.098, P=0.03$, ANOVA for the 50\%-reduction-time (c): $F=23.36, P=0.008$ while for the decline rate (d): $F=5.64, P=0.076$. On the other hand, amendment of Dutch organic soil with $S$. maltophilia enhanced the survival of $R$. solanacearum, MANOVA: Wilk's Lambda $=0.145$, $P=0.055$, ANOVA for the 50\%-reduction-time (c): $F=3.81, P=0.123$ and for the decline rate $(\mathrm{d})$ : $F=23.58, P=0.008$ (Fig. 3). 
Bacterial diversity in different soils

The bacterial diversity $S$ was significantly lower ( $t$-test; $P=0.005)$ in Egyptian organic than in the conventional soil while the Shannon-Wiener index $H^{\prime}$ did not significantly differ (Table 1 ). The reverse was true for the Dutch soils: $S$ was significantly higher in organic than in the conventional soil ( $t$-test, $P=0.031)$. There was no difference in $H^{\prime}$ between the Dutch soils. There was no significant correlation between $S$ and the 50\%-reduction-time $c$ or the decline rate $d$ of either of the decline curves for $S$. maltophilia and $R$. solanacearum. However, there was a significant negative correlation between $H^{\prime}$ and the decline rate $d$ for $R$. solanacearum $(r=-0.66$, $P=0.019$ ).

\section{Discussion}

For the first time, strains of $S$. maltophilia were found that inhibited $R$. solanacearum in vitro on agar plates and in vivo on potato plants grown in soil. The in vitro test revealed a possible production of antibiotics responsible for such inhibition. Stenotrophomonas maltophilia produces various antibiotics, for example, maltophilin, a macrocyclic lactam antibiotic, which has antifungal activity, but is inactive against Gram-positive and Gram-negative bacteria (Berg et al. 1996; Jakobi et al. 1996). Three other antibiotics produced by $S$. maltophilia have been characterized, namely xanthobaccin A, B, and $\mathrm{C}$, which have the same plain structure as maltophilin (Nakayama et al. 1999). These were effective against fungi and oomycetes, but not against the bacteria tested (Nakayama et al. 1999). Unfortunately $R$. solanacearum was not included in these tests. Apart from antibiotics, S. maltophilia produces lytic enzymes that have been implicated in biological control activity against fungi (Berg et al. 1996), for example chitinase (Zhang and Yuen 1999) and an extracellular proteolytic enzyme (Dunne et al. 2000). This last enzyme may also be active against $R$. solanacearum, as Gram-negative bacteria contain, next to lipopolysaccharide, Braun lipoprotein in their cell walls.

The inhibitory effect against $R$. solanacearum by the $S$. maltophilia strains used in this study was proven not to be based on siderophore production like that by P. fluorescens (Ran et al. 2005b), as the availability of iron affected only the antagonistic activity of $P$. fluorescens. The antibacterial efficiency of $P$. fluorescens depends at least partially on the production of the siderophore pseudobactin which can efficiently form complexes with iron in soils making it unavailable to plant pathogens, thus inhibiting their growth (Buyer and Leong 1986; Ciampi-Panno et al. 1989; Ran et al. 2005b). Jurkevich et al. (1992) found one isolate of $S$. maltophilia that was able to utilize $\mathrm{Fe}^{3+}$ in the siderophore pseudobactin as the sole iron source, but only to a limited extent. It is not known if $S$. maltophilia produces its own siderophore.

The antagonistic isolates of $S$. maltophilia used in this work were easily recovered from the rhizosphere of eggplant but not from that of sweet pepper. These two solanaceous crops have been listed among the plant species susceptible to race 1 of $R$. solancearum (Kelman 1953). Race 3 of the pathogen, used in this work, is known to affect potatoes and tomato (Buddenhagen and Kelman 1964). This race may variably infect other host plants under greenhouse conditions, especially less compatible hosts under high soil infestation levels. Thus, S. maltophilia probably did not evolve as a specific antagonist of race 3 of $R$. solanacearum on eggplant. However, $S$. maltophilia is known to be a good rhizosphere colonizer (Juhnke et al. 1987), and is a common member in the rhizosphere of many plants (Berg et al. 1996), especially of plants with high concentrations of sulphur-containing compounds such as methionine in their rhizosphere (Debette and Blondeau 1980). Our S. maltophilia strains were able to produce $\mathrm{H}_{2} \mathrm{~S}$, which would be beneficial in rhizospheres rich in sulphur-containing compounds, especially under moist, reducing conditions.

The antagonistic $S$. maltophilia strains were much more effective in controlling $R$. solanacearum in Egyptian clay soils than in Dutch clay soils, where they did not have significant suppressive effects on brown rot development. Thus, the antagonistic strain was effective in the soil from which it was isolated, probably because it co-evolved with the plants that were grown in the Nile Delta for centuries. Moreover, S. maltophilia survived significantly better in Egyptian than in Dutch clay soils, while $R$. solanacearum survived better in Dutch than in Egyptian soils, which may be related to clay and organic matter content, 
which were both higher in the Egyptian soils. A high organic matter content was shown to be detrimental to R. solanacearum (Balabel et al. 2005). Moreover, S. maltophilia may not have survived long enough to be able to control $R$. solanacearum in the Dutch soils. A similar conclusion had been drawn previously about the failure of other potential biocontrol agents in controlling root pathogens in soil under greenhouse conditions (Weller 1988). Biocontrol agents selected in the laboratory often fail under field conditions (Fravel 1988). Factors affecting direct antagonism on agar media are usually not known, and the conditions that allow in vitro activity may not be present in nature (Wagih 1991). Thus, it was quite fortuitous to find strains that were effective in field soil (at least in Egyptian soil), although relatively few strains were originally tested in the laboratory.

The reasons for the differences in survival of $S$. maltophilia in the various soils are not clear. The nitrate and ammonium contents and the $\mathrm{pH}$ of the Egyptian soils were higher than those of the Dutch soils. There was a positive correlation between survival of $S$. maltophilia and $\mathrm{pH}$, but not the available nitrogen content. On the other hand, there was a negative correlation between $R$. solanacearum survival and $\mathrm{pH}$, and also with $\mathrm{NO}_{3}$. There could have been indirect effects, with a greater sensitivity of $R$. solanacearum than $S$. maltophilia towards ammonia, which could have been higher in the high$\mathrm{pH}$ Egyptian soil. The percentages of clay and organic matter were also higher in the Egyptian soils, especially the organically managed Egyptian soil, than in the Dutch soils, and there was a positive correlation between the organic matter content and survival of $S$. maltophilia. Also in this case, there might have been an indirect effect, as the availability of organic matter can increase the activity of biocontrol agents (Hiddink et al. 2005; Hoitink and Boehm 1999), which may explain the better survival of the antagonist and the suppression of the pathogen by the antagonist in the Egyptian organic clay soil. The bacterial diversity in the Egyptian organic clay soil was less than in the conventional soil, which may explain the higher efficiency of the biocontrol agent in the Egyptian organic versus conventional soil (Hiddink et al. 2005). On the other hand, the antagonist enhanced the survival of the pathogen in the Dutch organic soil by delaying its decline phase. The biodiversity was higher in the organic than in the conventional Dutch soil, reducing the efficacy of $S$. maltophilia to suppress $R$. solanacearum, so that the pathogen could survive longer. Similarly, the biocontrol agent $P$. fluorescens declined faster and was less effective in controlling take-all disease, when added to organically managed soil with a diverse microbial community than in a biologically impoverished conventionally managed soil (Hiddink et al. 2005).

Stenotrophomonas maltophilia was more efficient at controlling the wilt disease for the early maturing susceptible cultivar Nicola, compared to the late maturing moderately tolerant Diamant (only tested in Egyptian soil). The relation between susceptibility to brown rot and maturity of the potato variety was addressed by Farag (1976). Root exudates of early maturing, disease susceptible potato varieties are known to be rich in amino acid content compared to late maturing, disease tolerant varieties, resulting in larger microbial populations in the rhizosphere of susceptible varieties compared to tolerant varieties (Farag et al. 1986). The quality and quantity of substrate available in the rhizosphere of plants greatly affect the establishment of biocontrol agents on plant roots (Hoitink and Boehm 1999), suggesting that roots of Nicola may have been better colonized by $S$. maltophilia than those of Diamant.

The practical implication of this work is that $S$. maltophilia could be used as biological control agent in the Nile Delta of Egypt where the disease is endemic. This could be accomplished either by stimulating naturally occurring populations, for example by crop rotation or intercropping with crops that have high concentrations of sulphur-containing amino acids in their root exudates, or by application of selected antagonistic S. maltophilia strains, for example by bacterization of potato tubers. However, the production of $S$. maltophilia for biological control would need to be approved by the appropriate regulatory agencies, as certain strains of $S$. maltophilia have been associated with various illnesses in immuno-depressed human patients (Berg et al. 2005).

Acknowledgements This project was funded by the EU through the EU-Egypt Potato Brown Rot Project Phase II (SEM03/220/51A / EGY 1B/1999/0192). We appreciate the advisory and technical help from the team at the Department of Bacteriology of the Plant Protection Service (PD), Wageningen, namely B. Briaire, G. Willemsen, J.G.B. Voogd, N.M. Landman, P. van de Werde, P.P.M.A. GorkinkSmits, and S. Somovilla-Carrasco. We are grateful to H.D. 
Halm and O. de Vos of the Biological Farming Systems Group for technical assistance. We are also grateful to the AIO group at the Biological Farming Systems Department of Wageningen University for advisory help via the discussion group meetings. We also appreciate the cooperative help and the valuable advices from Dr Faiza.G. Fawzy from the Potato Brown Rot Project in Egypt.

\section{References}

Allen, R. N. (1957). Experiments in soil bacteriology (3rd revised ed.) Minneapolis, Minnesota, USA: Burgess Publishing Co.

Anon. (1998). Interim Testing Scheme for the Diagnosis, Detection and Identification of Ralstonia solanacearum (Smith) Yabuuchi et al. in Potatoes. Annex II to the Council Directive 98/57/EC of 20 July 1998 on the Control of Ralstonia solanacearum (Smith) Yabuuchi et al. Publication 97/647/EC. Official Journal of the European Communities No. L 235, 8-39.

Aspiras, R. B., \& De-la Cruz, A. R. (1986). Potential biological control of bacterial wilt in tomato and potato with Bacillus polymyxa FU6 and Pseudomonas fluorescens. In G. J. Persley (Ed.), Bacterial Wilt disease in Asia and the South Pacific. ACIAR proceedings 13 (pp. 89-92). Canberra: ACIAR.

Balabel, N. M., Ewed, W. E., Mostapha, M. I., \& Farag, N. S. (2005). Some epidemiological aspects of Ralstonia solanacearum. Egyptian Journal of Agricultural Research, $83,1547-1563$

Bapat, S., \& Shah, A. K. (2000). Biological control of fusarial wilt of pigeon pea by Bacillus brevis. Canadian Journal of Microbiology, 46, 125-132.

Berg, G., Eberl, L., \& Hartmann, A. (2005). The rhizosphere as a reservoir for opportunistic human pathogenic bacteria. Environmental Microbiology, 7, 1673-1685.

Berg, G., Marten, P., \& Ballin, G. (1996). Stenotrophomonas maltophilia in the rhizosphere of oilseed rape - occurrence, characterization and interaction with phytopathogenic fungi. Microbiological Research, 151, 19-27.

Briton-Jones, H. R. (1925). Mycological work in Egypt during the period 1920-1922. Egypt Ministry of Agriculture Technical and Scientific Bulletin 49. Cairo, Egypt.

Buddenhagen, I. W., \& Kelman, A. (1964). Biological and physiological aspects of bacterial wilt caused by Pseudomonas solanacearum. Annual Review of Phytopathology, 2, 203-230.

Buyer, J. S., \& Leong, J. (1986). Iron transport-mediated antagonism between plant growth-promoting and plantdeleterious Pseudomonas strains. Journal of Biological Chemistry, 261, 791-794.

Campbell, J. N., Conn, K., Sorlie, L., \& Cook, F. D. (1986). Inhibition of growth in canola seedlings caused by an opportunistic Pseudomonas sp. under laboratory and field conditions. Canadian Journal of Microbiology, 32, 201207.

Ciampi-Panno, L., Fernandez, C., Bustamante, B., Andrade, N., Ojeda, S., \& Contreras, A. (1989). Biological control of bacterial wilt of potatoes caused by Pseudomonas solanacearum. American Potato Journal, 66, 315-332.

Cook, D., \& Sequeira, L. (1994). Strain differentiation of Pseudomonas solanacearum by molecular genetic methods. In A. C. Hayward, \& G. L. Hartman (Eds.), Bacterial Wilt: The disease and Its causative agent, Pseudomonas solanacearum (pp. 77-93). Wallingford, UK: CAB International.

Dal Bello, G. M., Mónaco, C. I., \& Simón, M. R. (2002). Biological control of seedling blight of wheat caused by Fusarium graminearum with beneficial rhizosphere microorganisms. World Journal of Microbiology and Biotechnology, 19, 627-636.

Debette, J., \& Blondeau, R. (1980). Presence of Pseudomonas maltophilia in the rhizosphere of several cultivated plants. Canadian Journal of Microbiology, 26(4), 460-463.

Dowson, W. J. (1957). Plant disease due to bacteria (2nd ed.). Cambridge, UK: Cambridge University Press.

Dunne, C., Crowley, J. J., Moënne-Loccoz, Y., Dowling, D. N., de Bruijn, F. J., \& O'Gara, F. (1997). Biological control of Pythium ultimum by Stenotrophomonas maltophilia W81 is mediated by an extracellular proteolytic activity. Microbiology, 143, 3921-3931.

Dunne, C., Monne-Loccoz, Y., de Bruijn, F. J., \& O'Gara, F. (2000). Overproduction of an inducible extracellular serine protease improves biological control of Pythium ultimum by Stenotrophomonas maltophilia strain W81. Microbiology, 146, 2069-2078.

Eichner, C. A., Erb, R. W., Timmis, K. N., Wagner-Döbler, I. (1999). Thermal gradient gel electrophoresis analysis of bioprotection from pollutant shocks in the activated sludge microbial community. Applied and Environmental Microbiology, 65, 102-109.

Farag, N. S. (1970). Studies on brown rot of potato in Egypt. M.Sc. Thesis, Faculty of Agriculture. Egypt: Ain Shams University.

Farag, N. S. (1976). Interaction between some soil microflora and Pseudomonas solanacearum PhD Thesis, Faculty of Agriculture. Egypt: Ain Shams University.

Farag, N. S., Fawzi, F. G., El-Said, S. I. A., \& Mikhail, M. S. (1986). Streptomycin in relation to potato brown rot control. Acta Phytopatholgica et Entomologica Hungarica, 21, 115-122.

Farag, N. S., Lashin, S. M., All-Abdel, R. S., Shatta, H. M., \& Seif-Elyazal, A. M. (1982). Antibiotics and control of potato black leg and brown rot diseases. Agricultural Research Reviews, 60, 149-166.

Farag, N. S., Stead, D. E., \& Janse, J. D. (1999). Ralstonia (Pseudomonas) solanacearum race 3, biovar 2, detected in surface (irrigation) water in Egypt. Journal of Phytopathology, 147, 485-487.

Franz, E., van Diepeningen, A. D., de Vos, O. J., \& van Bruggen, A. H. C. (2005). Effects of cattle feeding regimen and soil management type on the fate of Escherichia coli 0157:H7 and Salmonella enterica serovar Typhimurium in manure, manure-amended soil, and lettuce. Applied and Environmental Microbiology, 71, 6165-6174.

Fravel, D. (1988). Role of antibiosis in the biocontrol of plant diseases. Annual Review of Phytopathology, 26, 75-91. 
Garbeva, P., van Overbeek, L. S., van Vuurde, J. W. L., \& Van Elsas, J. D. (2001). Analysis of endophytic bacterial communities of potato by plating and denaturing gradient gel electrophoresis (DGGE) of 16S rDNA based PCR fragments. Microbial Ecology, 41, 369-383.

Graham, J., Jones, D. A., \& Lloyd, A. B. (1979). Survival of Pseudomonas solanacearum in plant debris and in latently infected potato tubers. Phytopathology, 69, 1100-1103.

Gorissen, A., van Overbeek, L. S., \& van Elsas (2004). Pig slurry reduces the survival of Ralstonia solanacearum biovar 2 in soil. Canadian Journal of Microbiology, 50, 587-593.

Hartman, G. L., \& Elphinstone, J. G. (1994). Advances in the control of Pseudomonas solanacearum race 1 in major food crops. In A. C. Hayward, \& G. L. Hartman (Eds.), Bacterial Wilt: the disease and its causative agent, Pseudomonas solanacearum (pp. 157-178). Wallingford, UK: CAB International.

Hayward, A. C. (1991). Biology and epidemiology of bacterial wilt caused by Pseudomonas solanacearum. Annual Review of Phytopathology, 29, 65-87.

Heuer, H., \& Smalla, K. (1997). Application of denaturing gradient gel electrophoresis for studying soil microbial communities. In J. D. van Elsas, J. T. Trevors, \& E. M. H. Wellington (Eds.), Modern soil microbiology (pp. 353373). New York: Marcel Dekker Inc.

Hiddink, G. A., van Bruggen, A. H. C., Termorshuizen, A. J., Raaijmakers, J. M., \& Semenov, A. V. (2005). Effect of organic management of soils on suppressiveness to Gaeumannomyces graminis var. tritici and its antagonist, Pseudomonas fluorescens. European Journal of Plant Pathology, 113, 417-435.

Hoitink, H. A. J., \& Boehm, M. J. (1999). Biocontrol within the context of soil microbial communities: A substratedependent phenomenon. Annual Review of Phytopathology, 37, 427-446.

Holt J. G., Krieg N. R., Sneath P. H. A., Staley J. T., Williams S. T. (Eds.), (1994). Bergey's manual of determinative bacteriology (9th ed.). Baltimore, USA: Williams \& Wilkins.

Houba, V. J. G., \& Novozamsky, I. (1998). Influence of storage time and temperature of dry soils on $\mathrm{pH}$ and extractable nutrients using $0.01 \mathrm{~mol} / 1 \mathrm{CaCl}_{2}$. Fresenius' Journal of Analytical Chemistry, 360, 362-365.

Houba, V. J. G., van der Lee, J. J., \& Novozamsky, I. (1997). Determination of organic matter content. Soil analysis procedures, other procedures. Soil and Plant Analysis, part 5B (pp. 38-40). Wageningen Agricultural University, Department of Soil Science and Plant Nutrition, Wageningen, the Netherlands.

Islam, T. M. D., \& Toyota, K. (2004). Suppression of bacterial wilt of tomato by Ralstonia solanacearum by incorporation of composts in soil and possible mechanisms. Microbes and Environment, 19, 53-60.

Jakobi, M., Winkelmann, G., Kaiser, D., Kempler, C., Jung, G., Berg, G., \& Bahl, H. (1996). Maltophilin: a new antifungal compound produced by Stenotrophomonas maltophilia R3089. Journal of Antibiotics (Tokyo), 49, 1101-1104.

Janse, J. D. (1988). A detection method for Pseudomonas solanacearum in symptomless potato tubers and some data on its sensitivity and specificity. EPPO Bulletin, 18, 343-351.

Janse, J. D. (1991). Infra- and intraspecific classification of Pseudomonas solanacearum strains, using whole cell fatty acid analysis. Systematic and Applied Microbiology, 14, 335-345.

Janse, J. D. (1996). Potato brown rot in Western Europe history, present occurrence and some remarks on possible origin, epidemiology and control strategies. EPPO Bulletin, 26, 679-695.

Janse, J. D., Arulappan, F. A. X., Schans, J., Wenneker, M., \& Westerhuis, W. (1998). Experiences with bacterial brown rot Ralstonia solanacearum biovar 2, race 3 in The Netherlands. In P. Prior, C. Allen, J. G. Elphinstone (Eds.), Bacterial Wilt disease. Molecular and ecological aspects (pp. 146-152). Heidelberg, Germany: Springer-Verlag.

Juhnke, M. E., Mathre, D. E., \& Sands, D. C. (1987). Identification and characterization of rhizosphere-competent bacteria of wheat. Applied and Environmental Microbiology, 53, 2793-2799.

Jurkevitch, E., Hadar, Y., \& Chen, Y. (1992). Differential siderophore utilization and iron uptake by soil and rhizosphere bacteria. Applied and Environmental Microbiology, 58, 119-124.

Kelman, A. (1953). The bacterial wilt caused by Pseudomonas solanacearum. North Carolina Agricultural Experimental Station Techical Bulletin, 99, 194.

Lambert, B., \& Joos, H. (1989). Fundamental aspects of rhizobacterial plant growth promotion research. Trends in Biotechnology, 7, 215-219.

Lopez, M. M., \& Biosca, E. G. (2004). Potato bacterial wilt management: new prospects for an old problem. In C. Allen, P. Prior, \& A. C. Hayward (Eds.), Bacterial Wilt Disease and the Ralstonia species complex (pp. 205-224). St. Paul Minnesota, USA: APS press.

Mendoza, H. A. (1994). Development of potatoes with multiple resistance to biotic and abiotic stresses: the International Potato Center Approach. In G. W. Zehnder, M. L. Powelson \& R. Jansson (Eds.), Advances in Potato Pest Biology and Management (pp. 627-642). St Paul, MN, USA: APS Press.

Michel, V. V., \& Mew, T. W. (1998). Effect of a soil amendment on the survival of Ralstonia solanacearum in different soils. Phytopathology, 88, 300-305.

Mickail, K. Y., Bishay, F., Farag, N. S., \& Tawfik, A. E. (1974). Evaluation of bacterial wilt disease in A.R.E. during the years from 1967-1968 to 1971-1972. Agricultural Research Review (Cairo), 52, 89-94.

Mickail, K. Y., Bishay, F., Farag, N. S., Tawfik, A. E., \& Fawzi, F. G. (1985). Status of brown rot disease of potatoes in Egypt in the years from 1980 to 1984. Agricultural Research Review (Cairo), 63, 165-174.

Murakoshi, S., \& Takahashi, M. (1984). Trials of some control of tomato wilt caused by Pseudomonas solanacearum. Bulletin of the Kanagawa Horticultural Experiment Station, 31, 50-56.

Nakayama, T., Homma, Y., Hashidoko, Y., Mizutani, J., \& Tahara, S. (1999). Possible role of xanthobaccins produced by Stenotrophomonas sp. Strain SB-K88 in suppression of sugar beet damping-off disease. Applied and Environmental Microbiology, 65, 4334-4339. 
Prior, P., \& Fegan, M. (2005). Recent developments in the phylogeny and classification of Ralstonia solanacearum. Acta Horticulturae (ISHS), 695, 127-136.

Priou, S., Gutarra, L., \& Aley, P. (1999). Highly sensitive detection of Ralstonia solanacearum in latently infected potato tubers by post-enrichment enzyme-linked immunosorobent assay on nitrocellulose membrane. EPPO Bulletin, 29, 117-125.

Ran, L. X., Li, Z. N., Wu, G. J., van Loon, L. C., \& Bakker, P. A. H. M. (2005a). Induction of systemic resistance against bacterial wilt in Eucalyptus urophylla by fluorescent Pseudomonas spp. European Journal of Plant Pathology, $113,59-70$.

Ran, L. X., Liu, C. Y., Wu, G. J., van Loon, L. C., \& Bakker, P. A. H. M. (2005b). Suppression of bacterial wilt in Eucalyptus urophylla by fluorescent Pseudomonas spp. in China. Biological Control, 32, 111-120.

Rhodes, D. J., \& Logan, C. (1987). A method for selecting fluorescent pseudomonads inhibitory to seed tuber decay. Potato Research, 30, 603-611.

Satoh, K., \& Toyota, K. (2004). Comparison of disease suppressiveness of different soils with or without repeated application of organic matters toward bacterial wilt of tomato caused by Ralstonia solanacearum. Microbes and Environment, 19, 310-314.

Schaad, N. W. (Eds.), (1988). Laboratory Guide for Identification of Plant Pathogenic Bacteria (2nd ed.). St. Paul, MN, USA: American Phytopathological Society.

Schans, J., \& Steeghs, M. H. C. G. (1998). Strategy and results of eradication of brown rot in The Netherlands. EPPO Bulletin, 28, 121-133.

Stead, D. E. (1992). Grouping of plant-pathogenic and some other Pseudomonas spp. by using cellular fatty acid profiles. International Journal of Systematic Bacteriology, 42, 281-295.

Sturz, A. V., Ryan, D. A. J., Coffin, A. D., Matheson, B. G., Arsenault, W. J., Kimpinski, J., \& Christie, B. R. (2004). Stimulating disease suppression in soils: sulphate fertilizers can increase biodiversity and antibiosis of root zone bacteria against Streptomyces scabies. Soil Biology and Biochemistry, 36, 343-352.

Sunaina, V., Kishore, V., Shekhawat, G. S., \& Kumar, M. (1997). Control of bacterial wilt of potatoes in naturally infested soils by bacterial antagonists. Journal of Plant Disease and Protection, 104, 362-369.

van Diepeningen, A. D., de Vos, O. J., Korthals, G. W., \& van Bruggen, A. H. C. (2006). Effects of organic versus conventional management on chemical and biological parameters in agricultural soils. Applied Soil Ecology, 31, 120-135.

van Elsas, J. D., Kastelein, P., van Bekkum, P., van der Wolf, J. M., de Vries, P. M., \& van Overbeek, L. (2000). Survival Ralstonia solanacearum Biovar 2, the causative agent of potato brown rot, in field and microcosm soils in temperate climates. Phytopathology, 90, 1358-1366.

van Elsas, J. D., Kastelein, P., de Vries, P. M., \& van Overbeek, L. (2001). Effects of ecological factors on the survival and physiology of Ralstonia solanacearum bv. 2 in irrigation water. Canadian Journal of Microbiology, 47, 842-854.

Wagih, E. (1991). Neither indole acetic acid nor bacteriocin is apparently involved in the in vitro antagonism between the virulent and the avirulent strains of Pseudomonas solanacearum. Journal of Phytopathology, 123, 153-160.

Weller, D. M. (1988). Biological control of soilborne pathogens in the rhizosphere with bacteria. Annual Review of Phytopathology, 26, 379-407.

$\mathrm{Xu}$, G. W., \& Gross, D. C. (1986a). Selection of fluorescent pseudomonads antagonistic to Erwinia carotovora and suppressive of potato seed piece decay. Phytopathology, $76,414-422$.

Xu, G. W., \& Gross, D. C. (1986b). Field evaluations of the interactions among fluorescent pseudomonads, Erwinia carotovora and potato yield. Phytopathology, 76, 423430.

Yabuuchi, E., Kosako, Y., Yano, I., Hotta, H., \& Nishiuchi, Y. (1995). Transfer of two Burkholderia and an Alcaligenes species to Ralstonia Gen. Nov.: proposal of Ralstonia pickettii (Ralston, Palleroni and Doudoroff 1973) Comb. Nov., Ralstonia solanacearum (Smith 1896) Comb. Nov. and Ralstonia eutropha (Davis 1969) Comb. Nov. Microbiology and Immunology, 39, 897-904.

Zhang, Z., \& Yuen, G. Y. (1999). Biological control of Bipolaris sorokiniana on tall fescue by Stenotrophomonas maltophilia strain C3. Phytopathology, 89, 817-882. 